\title{
HUBUNGAN MASA KERJA DENGAN KAPASITAS VITAL PARU OPERATOR EMPAT STASIUN PENGISIAN BAHAN BAKAR UMUM (SPBU) KOTA YOGYAKARTA
}

\author{
Irvan Setiawan, Widodo Hariyono \\ Fakultas Kesehatan Masyarakat, Universitas Ahmad Dahlan, Yogyakarta
}

\begin{abstract}
Background: Motor vehicles contributed almost 100 percent plumbum, 70,5 percent of carbon monoxide, 8,89 percent oxide nitrogen, 18,34 percent hydro carbon and 1,33 percent particles. Many pollutants would cause bad effect especially to respiratory system. Air pollution in Yogyakarta city, were above norml threshold of air qualiy standards. One point area with with high air pollutionis in SPBU. The officers also had high risk to exposed danger chemicals especially plumbum by gasoline and gas emissions of motor vehicle that waiting queue refueling or vehicle departing after refueling. The longer someone worked so the more he has exosed the danger that generated by work environment.

The purpose of this study was to determine the relation between work period with lung vital capacity operator in four public refueling stations Yogyakarta city.

Methods: this study was analytic observational with kuantitatif methods. Design used cross sctonl. The sample of this study were operator four public refueling stations amount 43 persons. The measurements of lung vital capacity used electric spirometer and themeasure of work period used questionnaire. Data analsys used univariate and bivariate.

Result: there was a significant relation between work period with lung vital capacity operator in four public refueling Yogyakarta city with significancy value $(p)$ amount 0,018 with $p=0,018,<\alpha=005$, so Ho which states there is no relationship between work periods with lung vital capacity in four public refueling stations "rejected". Ha which states there is relationship between work periods with lung vtal capacity I four public refueling stations "accepted"

Conclusion: work periods had significant relation to lung vital capacity operator in four public stations in yyogyakarta city.
\end{abstract}

Keywords: work periode, lung vital capacity, public refueling station operator

\section{PENDAHULUAN}

Percepatan pertumbuhan disektor transportasi dapat dilihat dan dirasakan pengaruhnya terhadap kehidupan manusia, khususnya di wilayah kota besar. Kota sebagai pusat perekonomian bangsa menjadikan semua kegiatan dan aktivitas manusia berjalan cepat seiring dengan kebutuhan modernisasi kota tersebut. Dampak negatif yang didapatkan adalah tingginya tingkat polusi udara lingkungan kota, sebagai hasil emisi gas buangan kendaraan bermotor. Dilihat dari sumbernya, pencemaran udara terbesar berasal dari asap buangan kendaraan bermotor. ${ }^{1}$ Kendaraan bermotor menyumbang hampir 100 persen timbal, 70,50 persen carbon monoksida, 8,89 persen oksida nitrogen, 18,34 persen Hidro Karbon, serta 1,33 persen Partikel. ${ }^{2}$ Berbagai pencemaran udara tersebut akan memberikan efek yang sangat buruk terutama terhadap sistem pernafasan ${ }^{2}$. Pencemaran udara di Kota Yogyakarta, berada di atas ambang normal standar baku mutu udara. Salah satu titik area dengan pencemaran udara tinggi adalah di SPBU. Petugas ini juga memiliki risiko tinggi terpapar bahan kimia berbahaya khususnya timbal dari bensin dan emisi gas kendaraan bermotor yang sedang menunggu antrian pengisian bahan bakar, ataupun kendaraan yang berangkat setelah mengisi bensin. ${ }^{3}$ Posisi SPBU di Kota Yogyakarta yang berada 
dekat dengan jalan raya memudahkan petugas terpapar oleh emisi kendaraan bermotor yang melaju di jalan raya. Kejadian tersebut berlangsung terus menerus akan berdampak pada pengendapan gas emisi kendaraan bermotor dalam paru-paru karena terhirup oleh petugas SPBU sehingga menyebabkan penurunan kapasitas vital paru. Semakin lama seseorang dalam bekerja maka semakin banyak dia telah terpapar bahaya yang ditimbulkan oleh lingkungan kerja tersebut. ${ }^{4}$ Survei pendahuluan yang dilakukan tercatat 4 SPBU dengan jumlah petugas 86 orang. Rata-rata bekerja 8 jam sehari dan beberapa dari mereka merasa sering pusing, sakit kepala, mual dan sesak nafas pada saat bekerja. Tujuan penelitian ini adalah untuk mengetahui hubungan antara masa kerja dengan kapasitas vital paru operator di empat stasiun pengisian bahan bakar umum (SPBU) Kota Yogyakarta.

\section{METODE PENELITIAN}

Jenis penelitian adalah analitik observasional dengan metode kuantitatif. Desain (rancangan) penelitian yang digunakan adalah cross-sectional. Lokasi penelitian ini adalah di SPBU Bugisan, SPBU A.M Sangji, SPBU Kyai Mojo dan SPBU Gambiran Kota Yogyakarta. Penelitian ini dilaksanakan bulan Juni 2010.

\section{A. Populasi dan Sampel}

1) Populasi

Populasi dalam penelitian ini adalah Operator empat SPBU yang ada di kota Yogyakarta yang berjumlah 86 orang.

2) Sampel

Teknik pengambilan sampel yaitu probability sampling dengan metode cluster random sampling. ${ }^{5}$ Penelitian yang menggunakan studi cross-sectional jumlah sampel ditentukan dengan menggunakan rumus: ${ }^{6}$

$\mathrm{n}=\frac{\mathrm{Zá} / 2^{2} \cdot \mathrm{PQ}}{\mathrm{d}^{2}} \Rightarrow \mathrm{n}=\frac{(1,96)(0,5)(0,5)}{(0,15)^{2}}=42,78=43$

Keterangan :

$$
\begin{array}{ll}
\mathrm{n} & =\text { Besar sampel } \\
\text { Zá/2 } & =\text { Standar skor dengan tingkat kepercayaan } 95 \% \text { dipeoleh } 1,96 \\
\mathrm{P} & =\text { Perkiraan proporsi penyakit atau keadaan yang dicari }(0,5) \\
\mathrm{Q} & =1-\mathrm{P} \\
\mathrm{d} & =\text { tingkat ketepatan absolut yang diinginkan peneliti }(0,15)
\end{array}
$$

\section{B. Pengumpulan Data}

1) Data Primer

Data yang langsung diambil dari responden dengan menggunakan kuesioner yang telah dirancang berdasarkan kebutuhan peneliti.

2) Data Sekunder

Data yang diperoleh dari manajemen SPBU berupa jumlah operator SPBU dan informasi lain yang menunjang dalam penelitian ini.

\section{Analisis Data}

1) Analisis Univariat

Analisis univariat dilakukan untuk memperoleh gambaran umum dengan cara mendeskripsikan tiap-tiap variabel yang digunakan dalam penelitian yaitu dengan melihat gambaran distribusi frekuensinya dalam bentuk tabel.

2) Analisis Bivariat 
Analisis data yang digunakan dalam penelitian mengenai korelasi lama bekerja dengan kapasitas vital paru operator empat SPBU Kota Yogyakarta menggunakan pengujian hipotesis asosiatif untuk statistik nonparametrik (karena skala data yang digunakan adalah skala data ordinal) melalui uji korelasi Rank Spearman.

\section{HASIL DAN PEMBAHASAN}

\section{A. Hasil Penelitian}

\section{1) Karakteristik Responden}

a) Umur

Tabel 2. Karakteristik Responden Menurut Umur

\begin{tabular}{rll}
\hline Umur (Tahun) & Frekuensi & Persentase (\%) \\
\hline $15-20$ & 9 & 21 \\
\hline $21-25$ & 9 & 21 \\
\hline $26-30$ & 9 & 21 \\
\hline $31-35$ & 6 & 14 \\
\hline $36-40$ & 3 & 7 \\
\hline $41-45$ & 3 & 7 \\
\hline $46-50$ & 4 & 9 \\
\hline Jumlah & 43 & 100
\end{tabular}

Berdasarkan kategori diatas, kelompok umur terbanyak yang dijadikan sampel pada $15-20,21-25$ dan $26-30$ yaitu 9 responden (21\%), sedangkan kelompok umur yang paling sedikit dijadikan sampel pada 36-40 dan 41-45 yaitu 3 responden $(7 \%)$.

b) Jenis Kelamin

Tabel 3. Karakteristik Responden Menurut Jenis Kelamin

\begin{tabular}{cll}
\hline Jenis Kelamin & Frekuensi & Persentase (\%) \\
\hline Pria & 31 & 91 \\
\hline Wanita & 12 & 9 \\
\hline Jumlah & $\mathbf{4 3}$ & $\mathbf{1 0 0}$ \\
\hline
\end{tabular}

Berdasarkan diagram diatas, responden berjenis kelamin pria berjumlah 31 responden $(72 \%)$, sedangkan responden berjenis kelamin wanita berjumlah 12 responden (28\%).

\section{2) Masa Kerja Operator SPBU}

Berdasarkan data yang diperoleh, kondisi masa kerja operator SPBU sebagai berikut: 
Tabel 4. Distribusi responden menurut frekuensi masa kerja

\begin{tabular}{cll}
\hline Masa Kerja (thn) & Frekuensi & Persentase (\%) \\
\hline$<1$ & 5 & 12 \\
\hline $1-3$ & 14 & 32 \\
\hline$>3$ & 24 & 56 \\
\hline Jumlah & $\mathbf{4 3}$ & $\mathbf{1 0 0}$ \\
\hline
\end{tabular}

Masa kerja dengan frekuensi terbanyak adalah kategori masa kerja lama $(>3$ tahun) dengan jumlah 24 responden (56\%), dan untuk kategori masa kerja sedang (1-3 tahun) dengan jumlah 14 responden (32\%), sedangkan untuk kategori masa kerja baru $(<1)$ dengan jumlah 5 responden $(12 \%)$.

\section{3) Kapasitas Vital Paru Operator SPBU}

Berdasarkan pengukuran kapasitas vital paru pada 43 orang operator SPBU dengan menggunakan spirometer elektrik diperoleh hasil sebagai berikut:

Tabel 5. Distribusi Responden Menurut Frekuensi Kapasitas Vital Paru

\begin{tabular}{cll}
\hline Kapasitas Vital Paru (\%) & Frekuensi & Persentase (\%) \\
\hline$\geq 80(\mathrm{~N})$ & 26 & 60 \\
\hline $60-79(\mathrm{RR})$ & 13 & 30 \\
\hline $51-59(\mathrm{RS})$ & 3 & 7 \\
\hline$\leq 50(\mathrm{RB})$ & 1 & 3 \\
\hline Jumlah & $\mathbf{4 3}$ & $\mathbf{1 0 0}$ \\
\hline
\end{tabular}

Dari hasil penelitian menunjukkan, frekuensi terbanyak pada kategori $\geq 80 \%$ (Normal) yaitu sejumlah 26 responden (60\%), untuk kategori $60-79 \%$ (resriktif ringan) yaitu sejumlah 13 responden (30\%), sedangkan kategori $51-59 \%$ (resriktif sedang) yaitu 3 responden (7\%), sedangkan untuk kategori $\leq 50 \%$ (resriktif berat) yaitu 1 responden $(3 \%)$.

\section{4) Hubungan Masa Keja dengan Kapasitas Vital Paru Operator SPBU}

Tabel 12. Hubungan Masa Kerja Dengan Kapasitas Vital Paru Operator di 4 SPBU Kota Yogyakarta

\begin{tabular}{|c|c|c|c|c|c|c|c|c|c|c|c|c|c|}
\hline & & \multicolumn{8}{|c|}{ Kapasitas Vital Paru } & \multirow{2}{*}{\multicolumn{2}{|c|}{ Total }} & \multirow{3}{*}{$\mathbf{r}$} & \multirow{3}{*}{ Sig } \\
\hline \multicolumn{2}{|c|}{ Variabel } & \multicolumn{2}{|c|}{ RB } & \multicolumn{2}{|c|}{ RS } & \multicolumn{2}{|c|}{$\mathbf{R R}$} & \multicolumn{2}{|r|}{$\mathbf{N}$} & & & & \\
\hline & & $\mathrm{n}$ & $\%$ & $\mathrm{n}$ & $\%$ & $\mathrm{n}$ & $\%$ & $\mathrm{n}$ & $\%$ & $\mathrm{n}$ & $\%$ & & \\
\hline \multirow{3}{*}{$\begin{array}{l}\text { Masa } \\
\text { kerja }\end{array}$} & Lama & 0 & 0 & 2 & 4,65 & 12 & 27,91 & 10 & 23,25 & 24 & 55,81 & \multirow{4}{*}{$0,359 *$} & \multirow{4}{*}{0,018} \\
\hline & Sedang & 1 & 2,33 & 1 & 2,33 & 0 & 0 & 12 & 27,91 & 14 & 32,56 & & \\
\hline & baru & 0 & 0 & 0 & 0 & 1 & 2,33 & 4 & 9,30 & 5 & 11,63 & & \\
\hline \multicolumn{2}{|c|}{ Jumlah } & 1 & 2,33 & 3 & 6,98 & 13 & 30,23 & 26 & 60,46 & 43 & 100 & & \\
\hline
\end{tabular}

KES MAS Vol. 5, No. 3, September 2011: 162-232 
Keterangan: RB : Resriktif berat

RS : Resriktif Sedang

RR : Resriktif Ringan

$\mathrm{N}$ : Normal

Hasil analisis korelasi antara lama bekerja dengan kapasitas vital paru diperoleh nilai signifikansi $(p)$ sebesar 0,018 dengan $p=0,018<\alpha=0,05$ berarti dapat disimpulkan bahwa ada hubungan yang signifikan antara masa kerja dengan kapasitas vital paru.

\section{B. Pembahasan}

1) Masa Kerja Operator SPBU

Hasil penelitian menggunakan kuesioner didapat masa kerja responden berkisar antara < 1- 29 tahun dengan masa kerja minimal 4 bulan dan masa kerja maksimal 29 tahun. Masa kerja dapat berpengaruh positif dan negatif. Adapun yang berpengaruh positif adalah seseorang pekerja semakin terampil dalam melakukan pekerjaannya, sedangkan yang berpengaruh negatif bagi seseorang pekerja adalah semakin lama terpapar bahaya yang ditimbulkan oleh tempat kerja yang dapat mempengaruhi kesehatan terutama saluran pernafasan. $^{7}$

\section{2) Kapasitas Vital PAru Operator SPBU}

Hasil pengukuran kapasitas vital paru 43 responden menunjukkan, frekuensi terbanyak pada kategori $\geq 80 \%$ (Normal) yaitu sejumlah 26 responden $(60 \%)$, untuk kategori $60-79 \%$ (resriktif ringan) yaitu sejumlah 13 responden (30\%), sedangkan kategori $51-59 \%$ (resriktif sedang) yaitu 3 responden $(7 \%)$, sedangkan untuk kategori $\leq 50 \%$ (resriktif berat) yaitu 1 responden (3\%). Kapasitas vital sama dengan volume cadangan inspirasi dan volume cadangan ekspirasi, yaitu jumlah udara maksimum yang dapat di keluarkan seseorang dari paru, setelah terlebih dahulu mengisi paru secaramaksimum dan kemudian mengeluarkan sebanyak-banyaknya (kurang lebih 4600 mll) Semua volume dan kapasitas paru wanita kira-kira 20 sampai 25 persen di bawah pria. Dimana kapasitas vital rata-rata pria dewasa kira-kira 4,8 liter dan wanita dewasa 3,1 liter. $^{8}$

\section{3) Hubungan Masa Keja dengan Kapasitas Vital Paru Operator SPBU}

Hasil analisis korelasi antara lama bekerja dengan kapasitas vital paru diperoleh nilai signifikansi $(p)$ sebesar 0,018 dengan $p=0,018<\alpha=0,05$ berarti dapat disimpulkan bahwa ada hubungan yang signifikan antara masa kerja dengan kapasitas vital paru, hasil penelitian ini sesuai dengan teori yang menyatakan bahwa hubungan paparan efek bergantung pada lamanya paparan. ${ }^{9}$ Semakin lama seseorang dalam bekerja maka semakin banyak dia telah terpapar bahaya yang ditimbulkan oleh lingkungan kerja tersebut. ${ }^{4}$ Kondisi kerja tertentu yaitu dengan tingkat paparan yang tinggi, maka penyakit paru akan timbul bertahun-tahun setelah paparan.

Hasil penelitian menunjukkan operator SPBU dengan masa kerja lama sebanyak 24 orang, 12 orang mengalami resriktif ringan dan 2 orang mengalami resriktif sedang akan berisiko mengalami penurunan fungsi paru. Rata-rata operator memiliki jam kerja 8 jam perhari. Operator tersebut memiliki risiko tinggi terpapar bahan kimia berbahaya khususnya timbal dari bensin dan emisi gas kendaraan bermotor yang sedang menunggu antrian pengisisan 
bahan bakar, ataupun kendaraan yang berangkat setelah mengisi bensin. ${ }^{3}$ Kejadian tersebut berlangsung terus menerus akan berdampak pada pengendapan gas emisi kendaraan bermotor dalam paru-paru karena terhirup oleh petugas SPBU sehingga menyebabkan penurunan kapasitas vital paru.

Apabila kondisi paru terpapar dengan berbagai komponen pencemar, fungsi fisiologis paru sebagai organ utama pernafasan akan mengalami beberapa gangguan sebagai akibat dari pemaparan secara terus menerus dari berbagai komponen pencemar. Fungsi paru dapat berubah akibat sejumlah faktor non pekerjaan misalnya usia, jenis kelamin, tinggi badan, berat badan, kebiasaan merokok dan lain-lain. ${ }^{10}$

\section{SIMPULAN DAN SARAN}

\section{A. Simpulan}

Berdasarkan analisis korelasi antara lama bekerja dengan kapasitas vital paru diperoleh nilai signifikansi $(p)$ sebesar 0,018 dengan $p=0,018<\alpha=0,05$ berarti dapat disimpulkan bahwa ada hubungan yang signifikan antara masa kerja dengan kapasitas vital paru.

\section{B. Saran}

Bagi pihak menejer SPBU disarankan agar :

1) Hendaknya melakukan upaya preventif primer melalui pelaksanaan pemeriksaan berkala untuk mengetahui pajanan paparan pencemar terhadap fungsi paru pekerja. Setelah itu dapat dilakukan upaya preventif sekunder malalui Pengendalian kontak langsung terhadap paparan melalui penyediaan APD masker.

2) Pencegahan Tersier dapat ditempuh melalui Pembenahan kebijakan rotasi kerja secara proporsional dengan pengaturan waktu istirahat yang baik guna mengurangi paparan partikulat pencemar pada pekerja.

\section{DAFTAR PUSTAKA}

1. Riyadina, W., 1997, Pengaruh Pencemaran Pb (Plumbum) Terhadap Kesehatan, Media Litbangkes Vol. VII, Hal. 29-32.

2. Wardhana, W.A., 2004, Dampak Pencemaran Lingkungan, Andi Offset, Yogyakarta.

3. Mukono, H.J., 2005, Toksikologi Lingkungan, Airlangga University Press, Surabaya.

4. Suma'mur, PK., 1996, Higene Perusahaan dan Kesehatan Kerja, PT Gunung Agung, Jakarta.

5. Saryono, 2008, Metodologi Penelitian Kesehatan, Mitra Cendikia Press, Yogyakarta.

6. Riwidikdo, H., 2008, Statistik kesehatan, Mitra Cendikia Press, Yogyakarta.

7. Tulus, MA., 1995, Manajemen Sumber Daya Manusia, Gramedia Pustaka Utama, Jakarta.

8. Guyton., Hall, 1997, Buku ajar Fisiologi Kedokteran edisi 9, Alih Bahasa Oleh Irawati Setiawan, EGC, Jakarta.

9. Suyono, J., 1995, Deteksi Dini Penyakit Akibat Kerja, EGC, Jakarta.

10. Harrington,G., 2005, Buku Saku Kesehatan Kerja, EGC, Jakarta. 